\title{
APPLICATION OF REMOTE SENSING DATA FOR OIL SPILL MONITORING IN THE GUANABARA BAY, RIO DE JANEIRO, BRAZIL
}

\author{
CRISTINA MARIA BENTZ ${ }^{1}$ \\ FERNANDO PELLON DE MIRANDA ${ }^{1}$
}

${ }^{1}$ PETROBRAS/CEGEQ (Center of Excellence in Geochemistry - Ilha do Fundão, Cid. Universitária Qd.7, 21949-900, Rio de Janeiro, RJ, Brazil.

\begin{abstract}
This paper describes the application of remote sensing data for oil spill monitoring in the Guanabara Bay, Rio de Janeiro, Brazil. During the emergency, Landsat-5/TM (Thematic Mapper) and Radarsat-1 data were acquired to monitor the location of the spill and its movement. Image classification procedures have been utilized to highlight oil-covered areas on the water surface. Ambiguities in the oil detection were resolved with the aid of ancillary information in a GIS (Geographic Information System) environment. The results obtained helped PETROBRAS to optimize the emergency response procedures and subsequent cleaning efforts.
\end{abstract}

Key words: oil spill monitoring, emergency response, image classification

\section{Introduction}

The rupture of a pipeline transporting hydrocarbons at high temperature caused the spill of 1,300 $\mathrm{m}^{3}$ of fuel oil near the shoreline (Figure 1) on January 18, 2000, at 01:00 a.m., local time. Immediately after the accident, an emergency effort was undertaken to obtain satellite images in order to monitor the spill's location and movement. One Landsat-5/TM (Thematic Mapper) and 15 Radarsat-1 images were acquired. The low frequency of acquisition and the prevailing cloud cover limited the use of Landsat and Spot data. This paper presents the results obtained with the interpretation of the first three images acquired after the spill (Table 1).

Table 1

First Three Images Acquired to Monitor the Guanabara Bay Oil Spill

\begin{tabular}{|c|c|}
\hline Image & Acquisition (Local time) \\
\hline Radarsat-1 Standard 1 ASC & Jan 18, 2000, 19:20 \\
\hline Landsat-5/TM & Jan 19, 2000, 10:00 \\
\hline Radarsat-1 Standard 2 DES & Jan 26, 2000, 06:23 \\
\hline
\end{tabular}

The physical mechanism that allows detection of oil spills by spaceborne synthetic aperture radar (SAR) systems is the dampening of capillary waves on the ocean surface. These features have a few centimeters in wavelength and produce backscattering of the incident radar pulse due to a Bragg scattering mechanism (Johannessen et al., 1994). Therefore, ocean regions containing oil are dark in comparison with the background radar clutter. Although SAR images can be very useful for oil detection in the ocean, several other processes also produce regions of low radar backscatter which can lead to misinterpretation (Fingas and Brown, 1997; $\mathrm{Fu}$ and Holt, 1982). These processes are: (a) slicks caused by fresh water intrusions mostly of riverine origin; (b) regions of very weak or no wind; (c) shadow zones of 
waves behind structures, islands or land; (d) beds of underwater vegetation which calm the surface waters; (e) biogenic oils.

In the visible and reflected IR regions of the electromagnetic spectrum, oil slicks on the sea surface are detectable because of the changes in the light reflected back to the sensor at certain viewing angles. According to Berry and Prost (1999), the detection of slicks from space on visible imagery requires an angle between the look direction of the satellite and the center of the glint pattern smaller than $30^{\circ}$. Usually the presence of oil in the ocean increases the water surface reflectance, especially in the reflected IR bands (TM 4, 5 e 7) (Stringer et al., 1992).

\section{Image Processing and Interpretation}

Image processing techniques were applied to Radarsat-1 and Landsat-5/TM data in order to highlight oil-covered areas on the water surface. Ambiguities in the oil detection were resolved with the aid of ancillary information such as location of known sources of pollution, aerial inspection information and GPS controlled aerial photos taken from helicopters.

\subsection{Jan 18 Radarsat-1 (S1) Image}

The Radarsat-1 image acquired on Jan 18, 2000 (Figure 1) shows clearly the area affected by the spill accident. A textural classification procedure (Unsupervised Semivariogram Textural Classifier - USTC) was applied in order to enhance dark smooth areas. The algorithm generates new channels that represent the image textural information (Miranda et al., 1997). The isodata clustering algorithm was applied in order to carry out the unsupervised classification of this set of textural channels. After the unsupervised classification, results obtained from the clustering program were merged together through interactive class aggregation.

The dark smooth areas mapped with the classification procedure (Figure 2) were labeled as oil-free water, fluvial discharge or effluents, and oil-covered water. Ancillary information was an important aid to such an interpretation. Eighteen hours after the spill, the area of oil-covered water was approximately $33 \mathrm{~km}^{2}$.

\subsection{Jan 19 Landsat-5/TM Image}

One limitation to oil detection using the January 19, 2000, Landsat-5/TM image was the presence of clouds and haze near the spilled area. In order to improve the visual discrimination of patterns on the water surface related to oil, many RGB combinations of the seven TM bands were evaluated. One of the preferred band combinations for oil detection was the 1R2G3B (Figure 3). A supervised classification procedure (MAXVER) was applied in order to highlight the oil-covered surface. All TM bands were used in the classification.

The resulting image presents the following classes (Figure 4): oil-free water, fluvial discharge, bay areas affected by haze and oil-covered water. The area of oilcovered water thirty-four hours after the accident was approximately $56 \mathrm{~km}^{2}$. The oilcovered areas interpreted with remote sensing images were compared with the results of oil trajectory and fate models for model evaluation and calibration. 


\subsection{Jan 26 Radarsat-1 (S2) Image}

As the oil patch spread out around the bay (Figure 5), the detection of oil-covered areas were more difficult because of misinterpretations due to false targets, such as fresh water and sewerage intrusions, regions of very weak or no wind, shadow zones or biogenic oils. The unsupervised classification procedure applied in the Jan 26 image detected many dark smooth areas.

The integration of the classification results with ancillary information, such as location of know sources of pollution, aerial inspection information and GPS controlled aerial photos acquired simultaneously with image acquisition, allowed the final selection of oil-covered areas (Figure 6).

\section{Conclusions}

Radarsat-1 data provided a suitable temporal coverage for emergency monitoring of the Guanabara Bay oil spill.

Landsat data were effective to detect oil-covered areas. However, cloud cover and the 8-day revisit schedule (using both Landsat-5 and-7) prevents a systematic use as a monitoring tool.

Orbital remote sensing data were the most cost-effective tool to elaborate oil spill maps with cartographic precision.

Oil spill maps were used to assess the results of trajectory and fate models.

The use of ancillary information in a GIS environment is crucial to discriminate oil spill areas from false targets.

\section{References}

Berry, J.L. and Prost G.L., 1999, Hydrocarbon Exploration. In: Remote Sensing for the Earth Sciences, Manual of Remote Sensing, Third edition, Vol. 3.

Fingas, M., and C. Brown, 1997, Remote sensing of oil spill: Sea Technology, v. 38, p. 37-46.

Fu. L.L., and B. Holt, 1982, Seasat views oceans and sea ice with synthetic aperture radar: JPL Publication 81-120, 200 p.

Johannessen, J.A., Digranes, G., Espedal, H., Johannessen, O.M., Samuel, P., Browne, D., and Vachon, P., 1994, SAR Ocean Features Catalogue: ESSA SP1174, $106 \mathrm{p}$.

Miranda, F.P., Fonseca, L.E.N., Beisl, C.H., Rosenqvist, A., and Figueiredo, M.D.M.A.M., 1997, Seasonal mapping of flooding extent in the vicinity of the Balbina Dam (Central Amazonia) using RADARSAT-1 and JERS-1 SAR data. Proceedings of the International Symposium Geomatics in the Era of RADARSAT (GER'97), Ottawa, Canada, May 1997.

Stringer, W.J.; Dean, K.G.; Guritz, R.M.; Garbeil, H.M.; Groves, J.E. and Ahlnaes, K., 1992, Detection of Petroleum Spilled from the Mv Exxon Valdez: International Journal of Remote Sensing, 1992, vol. 13, NO. 5, 799-824. 


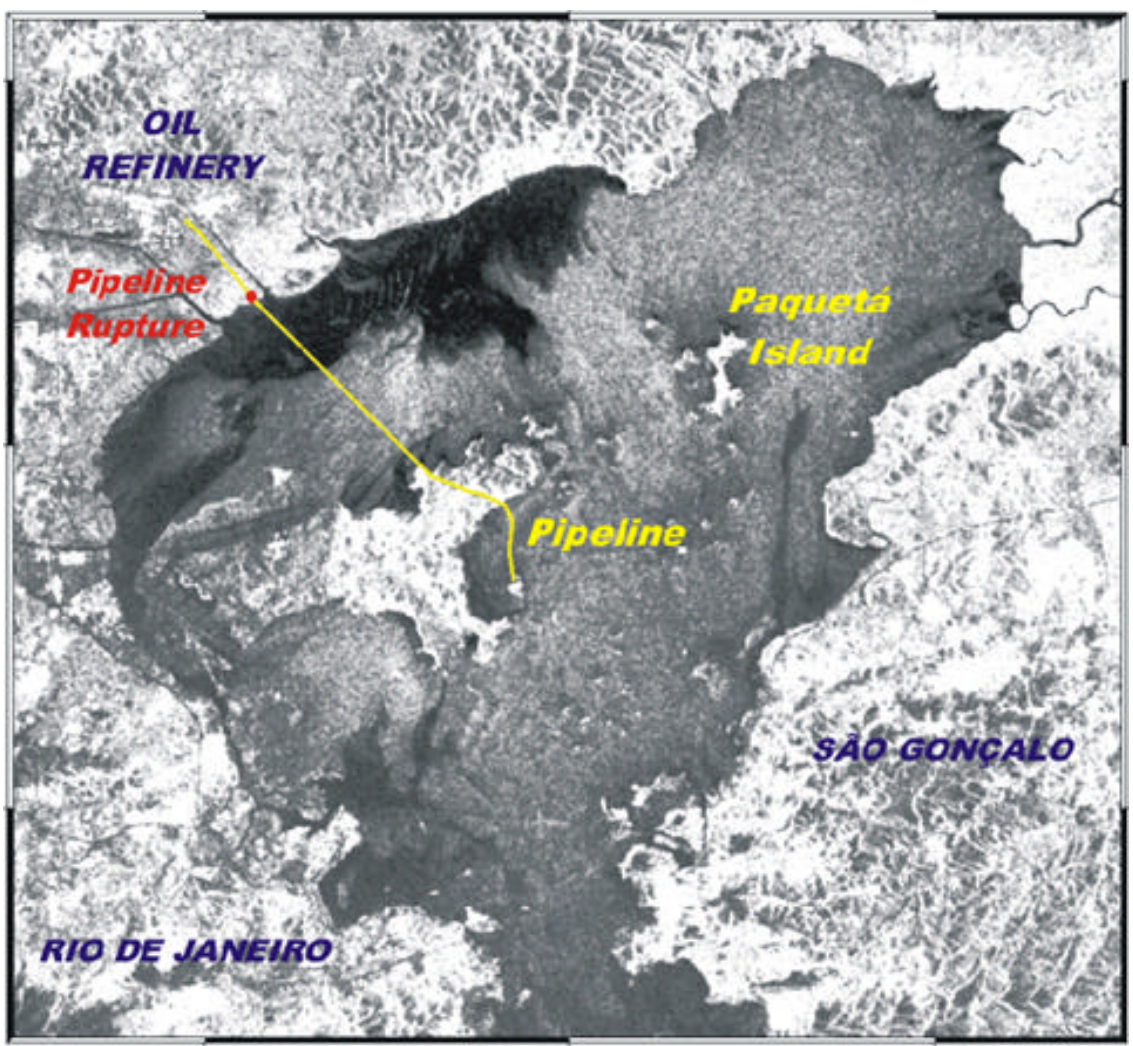

Figure 1 - Radarsat-1 (S1) image acquired on Jan 18, 2000, at 19:20 a.m., local time.

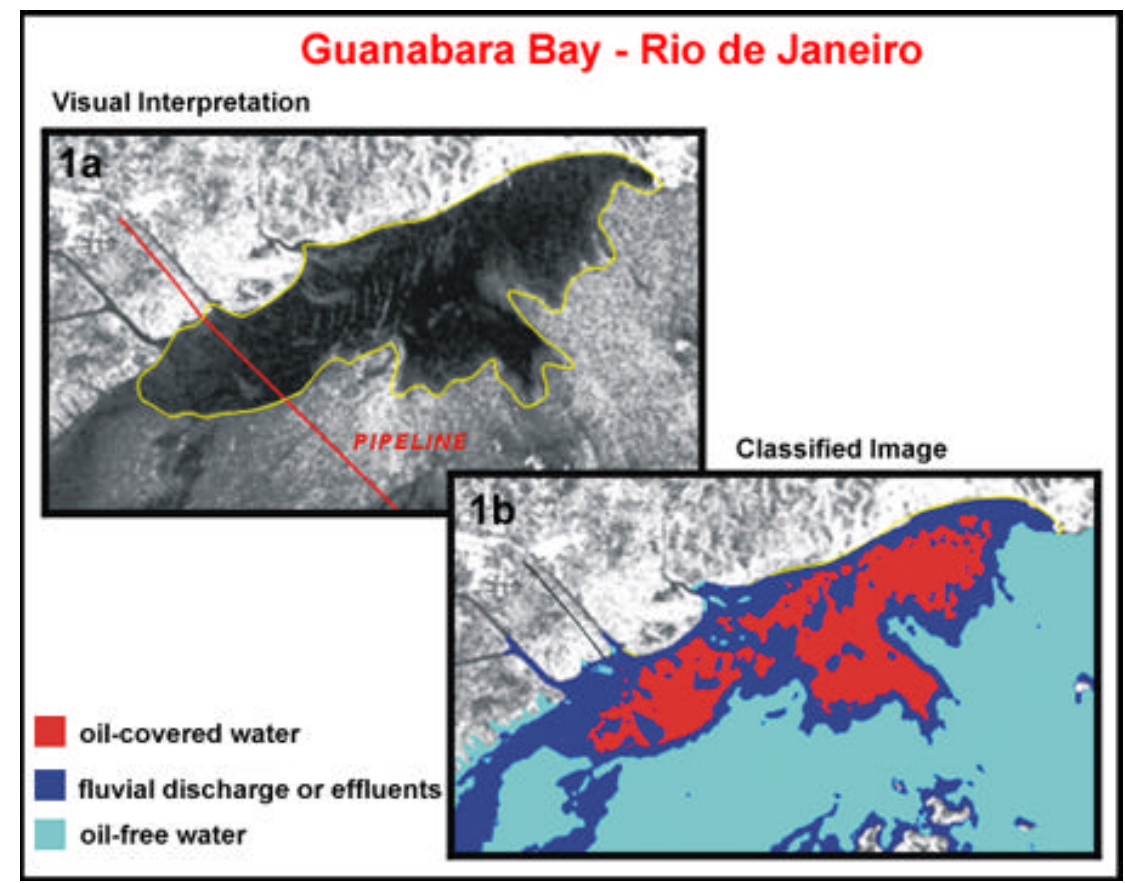

Figure 2 - Zoom of Radarsat-1 (S1) image acquired on Jan 18, 2000, at 19:20 a.m., local time, with visual interpretation of the oil-covered surface (1a). Result of the USTC classification procedure (1b). 


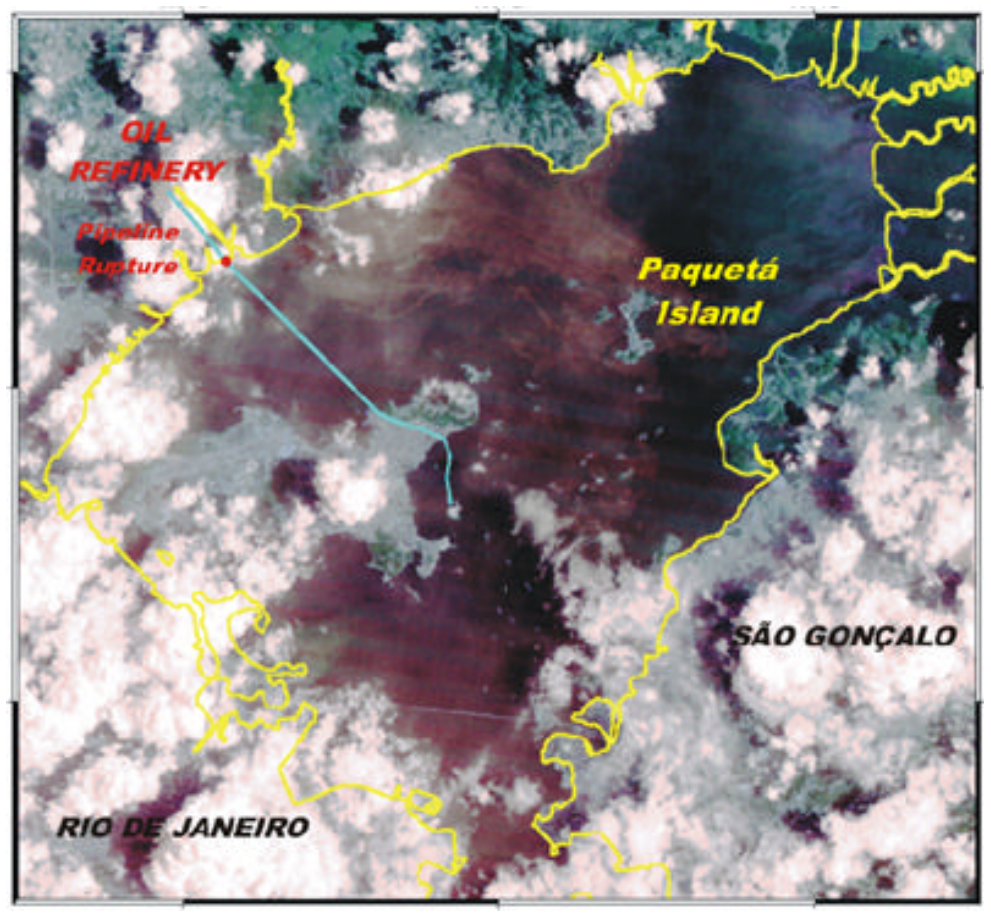

Figure 3- Landsat-5/TM image (1R2G3B) acquired on Jan 19, 2000, at 10:00 a.m., local time. The coastline is highlighted in yellow.

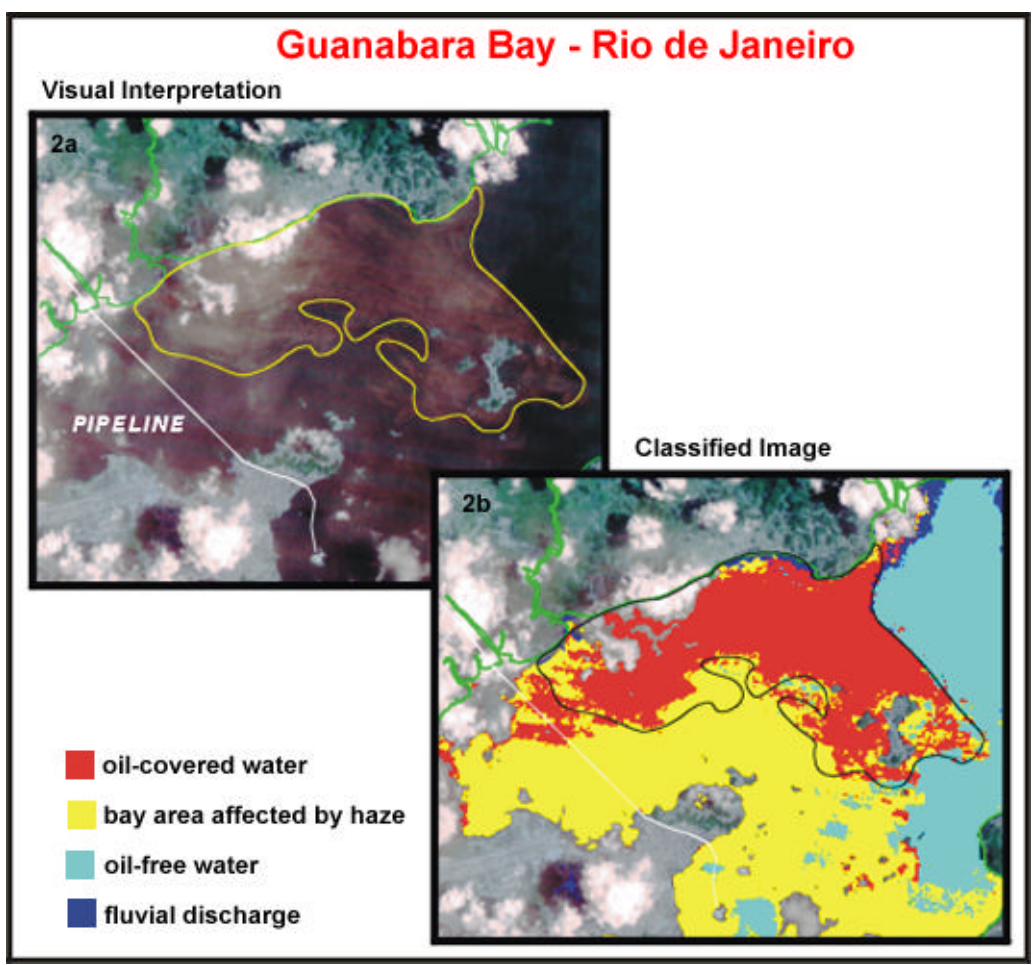

Figure 4- Landsat-5/TM image (1R2G3B) acquired on Jan 19, 2000, at 10:00 a.m., local time, with visual interpretation of the oil-covered surface (2a). Result of the MAXVER classification (2b). 


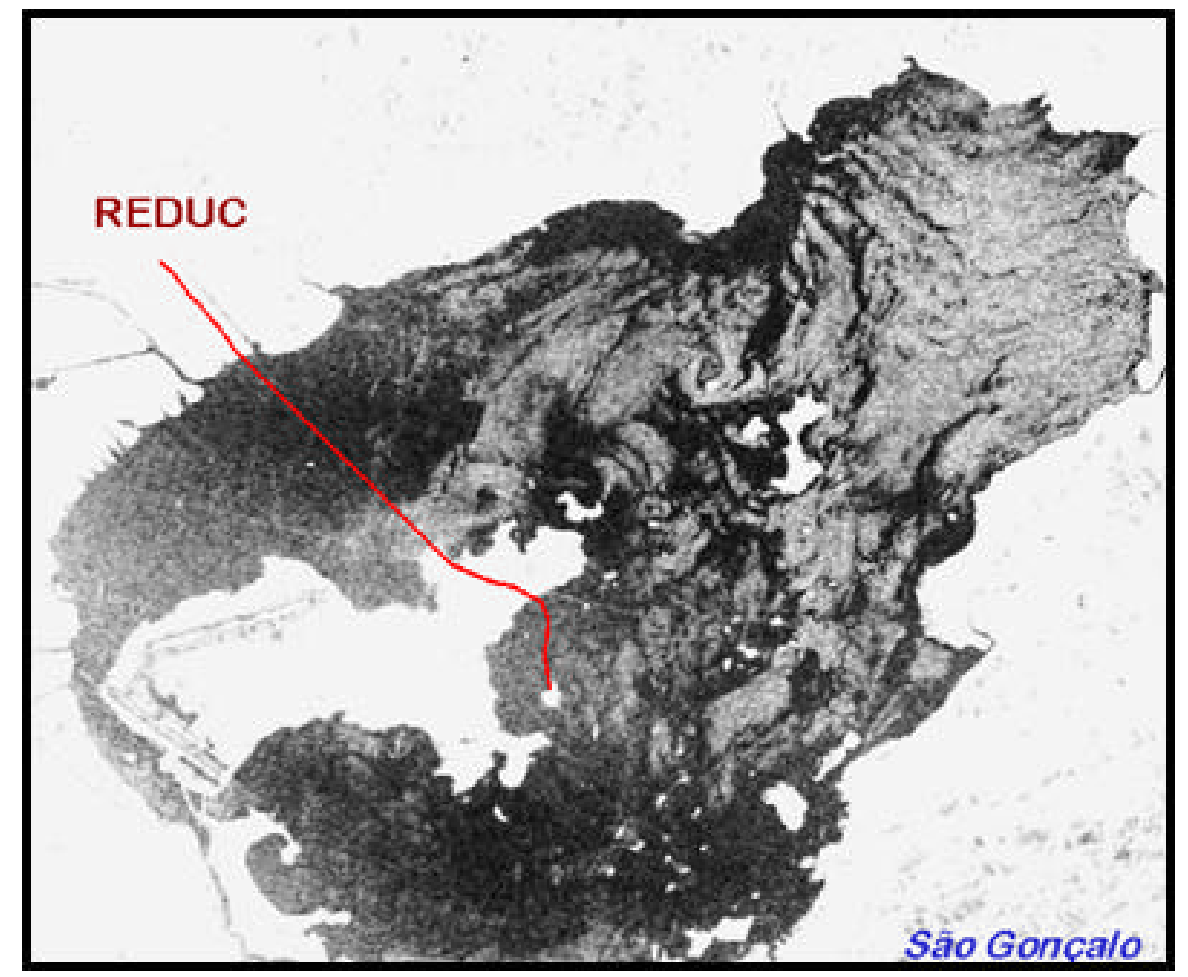

Figure 5- Radarsat-1 (S2) image acquired on Jan 26, 2000, at 06:23 a.m., local time.

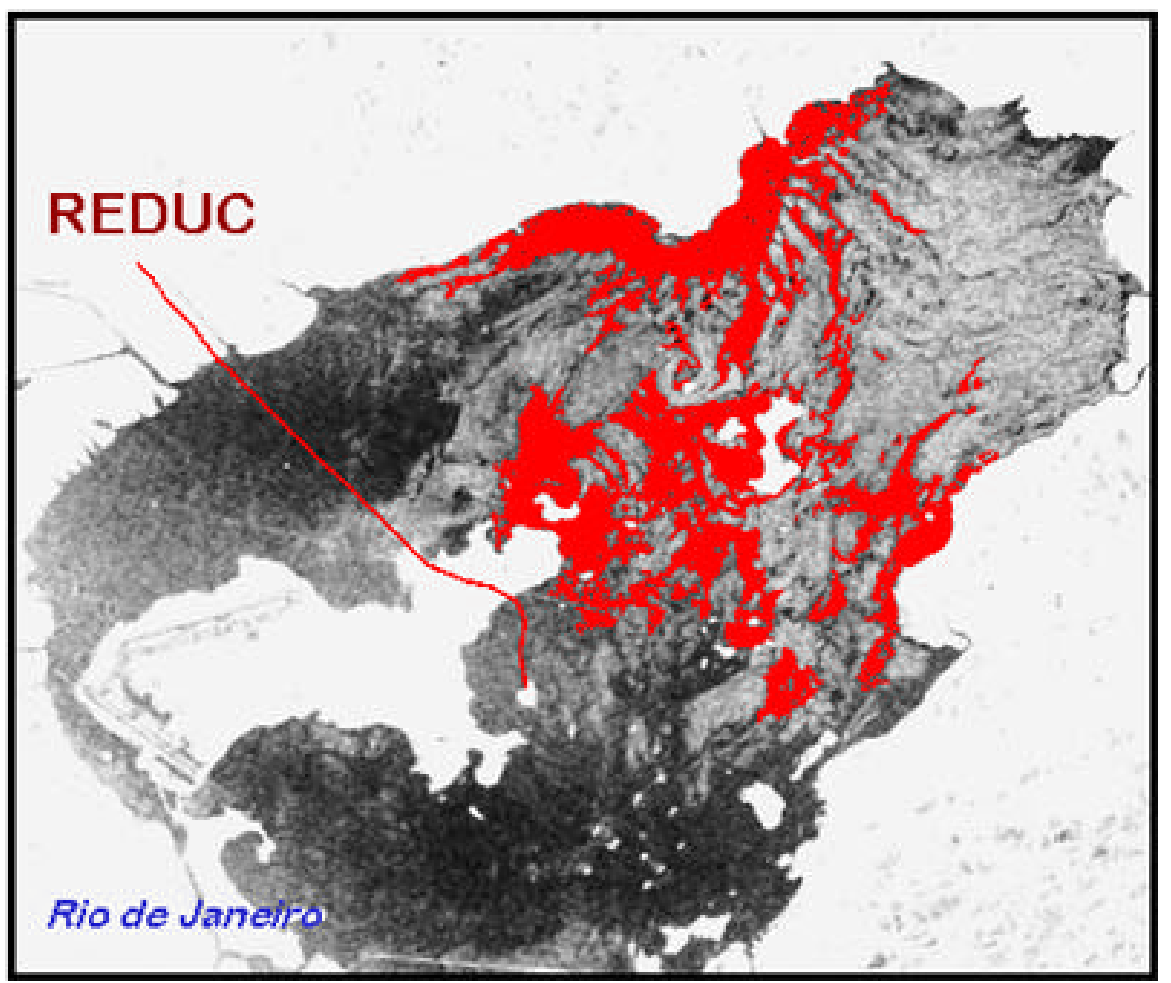

Figure 6- Radarsat-1 (S2) image acquired on Jan 26, 2000, at 06:23 a.m., local time. Interpreted oil-covered areas are highlighted in red. 